\title{
Correction to: Novel Cooling Rate Correlations in Molten Metal Gas Atomization
}

\author{
N. CIFTCI, N. ELLENDT, G. COULTHARD, E. SOARES BARRETO, L. MÄDLER, \\ and V. UHLENWINKEL
}

https://doi.org/10.1007/s11663-019-01534-y

(c) The Minerals, Metals \& Materials Society and ASM International 2019

\section{Correction to: Metallurgical and Materials Transactions B https://doi.org/10.1007/s11663-019-01508-0}

AUTHOR notes two typos in Eq. [2]. $\operatorname{Pr}^{1 / 3}$

The exponent " $1 / 3$ " moved above "Pr". It should be

Also, in subequation $\mathrm{Nu}=\left(h \cdot d_{\mathrm{E}}\right) / k_{\mathrm{g}}$ the variable $d_{\mathrm{E}}$ is incorrect. It should be $d_{\mathrm{p}}$ instead of $d_{\mathrm{E}}$.

Publisher's Note Springer Nature remains neutral with regard to jurisdictional claims in published maps and institutional affiliations.

N. CIFTCI is with the Leibniz Institute for Materials Engineering IWT, Badgasteiner Straße 3, 28359 Bremen, Germany. N. ELLENDT, G. COULTHARD, E. SOARES BARRETO, L. MÄDLER, and V. UHLENWINKEL are with the Faculty of Production Engineering, University of Bremen, Badgasteiner Straße 1, 28359 Bremen, Germany and also with the Leibniz Institute for Materials Engineering IWT. Contact e-mail: uhl@iwt.uni-bremen.de

The original article can be found online at https://doi.org/10.1007/ s11663-019-01508-0.

Article published online February 14, 2019. 